\title{
From co-actionality to extended intersubjectivity: Drawing on language change and ontogenetic development
}

\begin{abstract}
:
This paper combines research results centred on theory of mind (ToM) from cognitive and developmental psychology (e.g. Goldman 2006; Wilkinson \& Ball 2012; Apperly 2010) with the notion of intersubjectivity in usage-based linguistics (i.a. Verhagen 2005; Traugott 2012; Nuyts 2012). It identifies some of the controversies in the literature from both domains and suggests the desiderata for a hybrid approach to intersubjectivity, which is distinctively designed to tackle applied research in social and cognitive sciences. This model is based on a mismatch between interaction as mere 'co-action' vs interaction as spontaneously communicated awareness of an(other) mind(s). It provides a case study centred on the first language acquisition of pre-nominal usage of this/that and such. From respectively a distinctive collexeme (Gries and Stefanowitsch 2004a) and behavioural profile analysis (Gries 2010) will emerge that beyond expressions of joint attention, children ToM ability progressively underpins 'ad-hoc' generalised instantiations based on extended intersubjectivity (E-I), viz. the socio-cognitive skill to problematise what a general persona would act, feel or think in a specific context.
\end{abstract}

Keywords: intersubjectivity; theory of mind; per-locutionary effects; indexicality;

ontogenetic development

\section{Introduction}

This paper aims at combining experimental research centred on theory of mind (ToM) from cognitive psychology (e.g. Premack \& Woodruff 1978; Goldman 2006; Apperly 2010) with the notion of intersubjectivity in usage-based linguistics (i.a. Verhagen 2005; Traugott 2012; Nuyts 2012). It highlights some of the strengths and weaknesses in the literature from both domains and suggests the desiderata for a gradient and cross-disciplinary approach which can be applied in a number of neighbouring disciplines, e.g. cognitive psychology, forensic and social sciences. The present casestudy is centred on ontogenetic L1 data from the CHILDES ${ }^{1}$ database. It proposes an operational distinction between the 'behaviour-oriented' notion of co-actionality (cf. Reich 2011; Author 2016a, 2017b) and the 'ToM-oriented' one of intersubjectivity. Co-actional behaviour underpins target-

\footnotetext{
1 The CHILDES is a corpus serving as a central repository for first language acquisition data. It now has contents (transcripts, audio, and video) in 26 languages from 130 different corpora, all of which are publicly available worldwide (http://childes.talkbank.org, last accessed 23/07/2017).
} 
oriented joint projects (i.a. Clark 1996) involving at least 2 agents and may be performed without marked functions signalling Speaker/writer's (Sp/w) awareness of Addressee/reader's (Ad/r) emotions or beliefs. It is no secret that communication occurring as co-actional engagement is possible in both low and high levels of the autistic spectrum (e.g. Happe 1995; Grant, Riggs \& Boucher 2004; Bowler \& Benton 2005). Similarly infants and children younger than 3-4 are able to engage in dialogic and/or behavioural activities involving joint attention before being able to pass false-belief tests (e.g. O'Neill 1996; Moll \& Tomasello 2007). In light of this, the present paper proposes a new applied corpus-based approach addressing ToM as a gradient mechanism, shifting from mere co-actional joint attention to more inferential construing of specific and/or general personas' minds.

This study is structured as follows: section 2 focuses on ToM as it is traditionally described and enquired in cognitive psychology. Section 3 looks at the similar notion of intersubjectivity and the way this concept has been addressed in the linguistics literature. Section 4 suggests the desiderata for a hybrid approach to ToM which could combine experimental findings from from cognitive psychology together with a corpus-based methodology drawing on language change and ontogenetic development. In the same section I will propose an operational distinction between the behaviourbased notion of co-actionality and the more complex one of intersubjectivity. Section 5 is finally centred on a case study shedding light on the gradient formation of ToM in language change and ontogeny. A corpus-based enquiry of this, that and such from the English section of the CHLDES corpus provides evidence about the semasiological and ontogenetic shift from co-actionality to different construals of intersubjectivity. The computational modelling of this study combines distinctive collexeme methods (cf. Gries and Stefanowitsch 2004a) in sections 5.4 and 5.5 with a more holistic behavioural profile analysis (e.g. Gries 2010; Gries \& Otani 2010; Jansegers \& Gries 201) in section 5.6.

\section{Theory of Mind in Cognitive psychology}

Theory of mind (ToM) refers to the ability to problematise another person's mental states. In the literature in cognitive psychology it is generally agreed that neurotypical children around of 4 tend to be able to 'read' other people's minds to their decisions, e.g. making assumptions about people's knowledge, beliefs, feelings and intentions in order to interpret their behaviour ( Onishi \& Baillargeon, 2005; Kovács Téglás, \& Endress 2010; Surian, Caldi, \& Sperber, 2007). Most of research from cognitive psychology during the last 3 decades has relied heavily on different versions of so-called "false-belief" tasks (Baron-Cohen et al. 1985; Perner, Leekam, \& Wimmer, 1987; Wimmer \& Perner, 1983). Consider the following commonly used false-belief scenario: 
"Before Sally leaves for lunch, she hides her ball in the basket. While she is away eating, her big sister Anne plays a trick on her and moves her ball from the basket to the box. When Sally returns, where will she look for her ball? To succeed on the task, the participant needs to attribute a belief to Sally that she (falsely) believes the ball is in the basket and, on the basis of that false belief, will search in the basket, not in the box where the ball is really located and where the participant actually knows it to be. While many find this task trivial, not every-one passes: children who are 3years old or younger (Wellman, Cross, \& Watson, 2001) and children with autism (Baron-Cohen et al., 1985) fail to attribute a false belief, answering that Sally will search where the object really is, not where she thinks it is. Explaining these developmental and neuropsychological findings turns on understanding how the underlying neurocognitive mechanisms work".

(Cohen et al 2015: 50)

Based on the above, research focusing on ToM has not been moving beyond slight variations of a well established experimental paradigm (again, different versions of 'lab-bound' false-belief and perspective-taking task; trait judgments; social animations; judgments on photos of eyes or other nonverbal material). It is undeniable that this 'stimuli-driven' approach informed a heated debate about the nature of ToM (cf. Goldman 2006) and the developmental stage in which a ToM is acquired during ontogeny. However, much of the existing studies provide conflicting results concerning a number of issues: e.g. the phenomenological nature of ToM (whether based on a simulation or a folkpsychological theorising mechanism), the stage in which ToM emerges during ontogenetic development (e.g. roughly at the age of 4 or 2 years earlier?), whether a differentiation between implicit and explicit ToM is reasonable (e.g. Perner \& Ruffman 2005; Butterfill \& Apperly 2013) and how does it intersect with autism (cf. Stich \& Nichols 1997; Apperly et al. 2008; Apperly 2010; Wilkinson \& Ball 2012 for specific overviews of the ToM 'impasse'). In some cases these controversies are due to experimental limitations in distinguishing between behaviour-based vs mental state-based mechanisms of action monitoring (cf. Apperly 2010). For instance, different versions perspective-taking tasks do not clarify whether 2 years old infants are able to predict the incoming action of an agent with a false-belief due to an 'implicit' understanding of the agent falsebeliefs or simply due to behavioural cues linking an agent to a subsequent action (cf. Perner \& Ruffman 2005: 215; Piovinelli \& Giambrone 1999; Penn \& Piovinelli 2007). Equally important, the very setting of experimental labs is itself an inhibitor for addressing ToM as a gradient phenomenon, as the experimenter is unavoidably him/herself 'an-other mind'.

The above are among the reasons why it is agreed that new desiderata to address ToM in cognitive psychology are needed (e.g. Apperly 2010; Wilkinson \& Ball 2012; Schaafsma et al. 2015), 
as ToM cannot be merely tested through simulation tasks and being implicitly treated as a spectatorbased theory. This paper stresses the importance to observe ToM as a mechanism that occurs spontaneously during an interaction, intersecting with spatial and contextual conditions (e.g. whether the speaker knows the addressee; whether s/he is in his/her presence; whether s/he is accounting for a specific or general 3rd party; whether the addressee is being involved in a co-action or is simply a listener, and so on).

\section{Intersubjectivity in pragmatics and cognitive linguistics}

All the above being said about the experimental model in ToM, linguistic research on intersubjectivity is also a matter of controversial debate. The intersubjective paradigm in linguistics is presently still far from providing a consistent distinction between speakers' marked intentions to problematise the emotions/beliefs of other minds and propositional meanings that inherently include a deictic positioning of the speaker with respect to other personas in space. As an illustration, deictic elements such as this or that semantically encode joint attention among interlocutors (cf. Ferrari \& Sweetser 2012). This naturally leads to the question of whether spatial deictics should be considered as markers of intersubjectivity. In some accounts the answer is indeed positive (e.g. Diessel 2006; Breban 2010; Ghesquierre et al. 2012). However, this view is perhaps debatable when addressed from a crossdisciplinary perspective, as 1-2 year old infants do learn and actively use deictics before being able to pass ToM false-belief tasks. Intersubjectivity in the linguistics' literature is an extremely productive domain of research, yet it is defined, re-defined and re-interpreted depending on the authors dealing with it (i.a. Langacker 1991; Traugott 2003; Ghesquiere \& Van de Velde 2011).

Concerning the intersection between interlocutors' mutual awareness and spatial deixis Langacker $(1987,1990,1991)$ suggests that the use of pronouns such as $I$, we, or you have the function of foregrounding the speaker's communicative setting (what he defines as the ground) to identify the referent. In his approach, the conceptualisers' awareness of the here-and-now of the speech event can be semantically encoded by deictics that implicitly establish spatial relationships among speakers and objects. Similarly, demonstratives and determining elements like such and zulk are elsewhere also considered intersubjective, serving to create a "joint focus of attention" (Diessel 2006: 465) by which the speaker negotiates discourse referent tracking for the hearer (Ghesquière 2009, Ghesquire \& Van de Vede 2011).

Both Langacker's implicit account of the ground and the 'joint-attention approach' differ considerably from Traugott's diachronically informed definition of intersubjectivity, which she distinctively connects to meanings coding attention to the social self of the hearer (e.g. Traugott \& Dasher 2002). In Traugott's model, less-intersubjective constructions tend to progressively develop 
new polysemies with new intersubjectified functions. Discourse marking (DM) uses of actually or in fact are intersubjective as they mark not only connectivity between $\mathrm{p}$ and $\mathrm{q}$, but also function as a "DM hedge" to soften or mitigate what is said and acknowledge the addressee's actual or possible objections.

Verhagen $(2005,2007)$ proposes an alternative account of intersubjectivity specifically addressing cognitive coordination between speaker and hearer. An intersubjective construction foregrounds the hearer as active interpreter and conceptualiser of utterances of the speaker. This is the case of connectives such as but or moreover, which can be adopted to accommodate Ad/r's projected expectations through an interaction.

Nuyts (2001a, 2001b, 2012) holds another view on intersubjectivity which involves modal meanings "presented as being shared between the assessor and a wider group of people, possibly (but not necessarily) including the hearer" (Nuyts 2012: 58) as for constructions such as it is likely, unfortunately and so on. Drawing on that, Author (2013, 2017a) distinguishes meanings that are specifically aimed at addressing the $\mathrm{Ad} / \mathrm{r}$ 's potential reactions to what is said, from meanings that include a more or less general 3rd party, who conceptually functions as the social bearer of the utterance. The former are defined as immediate intersubjective (I-I) and diachronically precede further reanalysed functions encoding extended-intersubjectivity E-I. A case of I-I construction is the discourse marker (DM) actually when it specifically encodes Sp/w's awareness of a specific interlocutor:

\section{[pointing at a window]}

Actually, I wouldn't mind it staying open cos I'm a bit hot.

(BNC F7G 509)

(Author 2017: 95)

With the employment of actually $\mathrm{Sp} / \mathrm{w}$ prevents $\mathrm{Ad} / \mathrm{r}$ from disagreeing with the proposition, with an implied attempt to mitigate it. It could be paraphrased as Aware of what you might say, I am telling you $\mathrm{p}$. This is a case where $\mathrm{Sp} / \mathrm{w}$ 'reacts' to $\mathrm{Ad} / \mathrm{r}$ 's action (the opening of the window), with the awareness that 'sufficient shared understanding' (cf. Linell \& Lindstrom 2016) with Ad/r needs to be negotiated. Here the intersubjective awareness conveyed by actually in (1) does not exceed the hereand-now of the conversation. Consider now the case of actually in (2) below:

(2) They had to perhaps give up their pots and pans, or they were supposed to.

Actually, a remarkably few were collected, to provide brass for armaments. 
This usage of actually is an instance of a more extended form of intersubjectivity. Formally, it still functions as a discourse marker (DM), as it appears dislocated to a clause-periphery position (cf. Traugott 2012). However, while Sp/w's proposition also profiles the intent to prevent some virtual comment or objection by $\mathrm{Ad} / \mathrm{r}$, nonetheless, $\mathrm{Ad} / \mathrm{r}$ is no longer a specific interlocutor ( $\mathrm{s} / \mathrm{he}$ could be anyone). It also worth mentioning the research strand of interactional linguistics, where 'shared understanding' (Linell \& Lindstrom 2016) through communicative exchanges are tackled dialogically as context-depended strategies such as turn-parts of repair, reaction or expansion to achieve a socially shared cognition (Schlegoff 1991, 1992)

All in all, it is no secret that intersubjectivity in pragmatics and cognitive linguistics tends to be 'anchored' to a specific author's definition, as it is indeed challenging to view DMs like actually, connectives such as but or and, personal pronouns like $I$ or spatial deictics such as this or that or interactional strategies of repair all as markers of the same conceptual category. An obvious question naturally arises from such a variety of definitions and objects of enquiry:

\section{What is not intersubjective in language?}

And if the answer is nothing, a second question subsequently comes to mind:

If every linguistic phenomenon in a way or another can be arguably defined as intersubjective, what is the distinctive applicability of this concept?

The answer to this needs to be necessarily methodological. In fact, while debate is indeed necessary for the advance of a theory, however much of the controversies revolving around this concept are often detached from its correspondent notion of ToM in cognitive psychology and still show a tendency not to tackle 'applied' research. Intersubjectivity in quite a number of linguistic frameworks has become circular, viz. primarily based on linguistic criteria that vary according to the definition of each author. In this sense, it is important to find a way to exploit the important insights that we can get from the linguistic literature on intersubjectivity and combine them in a model that can be operationally applied in neighbouring disciplines, e.g. cognitive psychology, forensic and social sciences.

In the next sections I discuss the desiderata for a cross-disciplinary paradigm. Among them, I propose to account operationally for a gradient 'surplus approach' to address empirically whether the problematisation of (an-)other mind(s) is overtly codified as redundant structure or additional element 
to the mere 'co-actional' (cf. Reich 2011; Author 2016b) meaning of the utterance. From this perspective, the intersubjective dimension underpins all those linguistic elements that are 'unnecessary' for the simplest propositional realisation of a communicative act (entailing a basic 'coaction'), but which are needed to communicate the awareness of a specific addressee or a general third party's potential reactions to the utterance.

\section{Co-actionality vs. communicated intersubjectivity}

This section respectively focuses on the related notions of co-actionality and communicated intersubjectivity (cf. Author 2017b). The former draws on the evolutionary approach to linguistic acts as co-act proposals proposed in Reich $(2011,2012)$ and accounts for linguistic behaviour underpinning any shared activity or joint project (cf. Clark 1996) with a peer. Co-actional engagement regards 'interested' target-oriented speech events involving at least 2 agents and clearly may be performed without marked functions signalling the awareness of $\mathrm{Ad} / \mathrm{r}$ 's emotions or beliefs.

For instance, an agent may be interested in reaching the salt on a dining table with the help of someone sitting nearby. Whatever the utterance chosen by $\mathrm{Sp} / \mathrm{w}$, the two interlocutors will be involved in the co-action having to do with $\mathrm{Ad} / \mathrm{r}$ passing the salt to $\mathrm{Sp} / \mathrm{w}$. Yet, $\mathrm{Sp} / \mathrm{w}$ does not necessarily need to codify his/her awareness of $\mathrm{Ad} / \mathrm{r}$ 's state of mind while formulating the utterance: e.g. Pass me the salt; Could you please pass me the salt?; Salt, and so on. While all of these are coact proposals (cf. Reich 2011; Author 2016b) underpinning joint attention and a shared activity among agents, however not all of them encode a marked attempt to problematise $\mathrm{Ad} / \mathrm{r}$ 's state of mind. Simply put, not all of them communicate a process of "thinking about thought" (Apperly 2010: 76; ). In fact, it is noted that "humans all have a competence to make sense of the observed behaviour of others, a competence shared with many other animals" (Schaafsma at al. 2015: 65). Communication occurring as co-actional behaviour is proved to be possible in both low and high levels of the autistic spectrum (e.g. Happe 1995; Grant, Riggs \& Boucher 2004; Bowler \& Benton 2005). Infants and children younger than 3 are shown to be able to engage in dialogic and/or behavioural activities involving joint attention (e.g. O’Neill 1996; Moll \& Tomasello 2007). That being said, "simply knowing that someone's mental state differ from one's own is not necessarily the same as being explicitly aware of what the other person's mental state is". (c.f. Schneider et al. 2014, Bradford et al. 2015: 23). Explanations of successful performance in object-choice tasks based on social-cognitive capacities such as shared intentionality (Tomasello, 2008) and bodily mimesis (Zlatev, 2008; Zlatev et al. 2013) assume that these capacities precede language, in both hominid evolution and child development.

In light of these facts, a gradient redefinition of intersubjectivity as an 'overtly codified' dimension seems necessary. From the perspective of usage-based linguistics, it is both a theoretical 
and a methodological advantage to analyse ToM as an overtly codified phenomenon. ToM becomes marked as overt attempt to problematise a peer's emotions or beliefs and can thus be distinguished from mere attentional and behavioural ability in engaging in a co-action. It thus makes sense to propose that ToM is linguistically communicated when $\mathrm{Sp} / \mathrm{w}$ spontaneously (i.e. not prompted by an 'in-lab' stimulus) finds necessary to encode his/her awareness of $\mathrm{Ad} / \mathrm{r}$ 's as a distinctive effort or 'surplus' over mere target-oriented meaning: e.g. actually I'm a bit tired now vs. I'm tired (now) (cf. Traugott \& Dasher 2002 on the intersubjective functions of the discourse markers actually and a bit $o f^{2}$ ). As an illustration, it is beyond doubt that an imperative construction such as Look! establishes joint attention among the interlocutors. However, it is not purposely employed to problematise $\mathrm{Ad} / \mathrm{r}^{\prime} \mathrm{s}$ emotions or beliefs as when it is used as an intersubjectified attention-giving device (e.g. Romero Trillo 1997; De Clerk 2006: 168):

\section{Look!}

BNC KB1 5112

(4) Look Dani. You don't know what you're speaking about.

(Van Olmen 2010: 228)

In (4) Look is propositionally redundant at the co-actional level (e.g. it does not change the perlocutionary effects of the utterance and can be both semantically and grammatically omitted). However, from the point of view of Sp/w, look in (4) is needed at the intersubjective level: it allows $\mathrm{Sp} / \mathrm{w}$ to overtly account for the negative impact of the utterance towards Ad/r's 'positive face' (cf. Brown \& Levinson 1987). It is reasonable to expect a child younger than 4 being able to utter the former expression (3), while it is not farfetched to imagine the latter usage in (4) being 'cognitively' mastered at a later stage of language acquisition. The mismatch between (3) and (4) brings up a fundamental question of polysemy as diachronic stratification of meaning and the online ability of an individual to master different 'meaning potentials' (Norén \& Linell 2007; Linell \& Lindstrom 2016: $125)$ of the same construction. Crucially, semasiological change shows a tendency to develop ad-hoc functions of intersubjectivity (e.g. Traugott \& Dasher 2002): in the case above (4) is a reanalysed, comparatively more recent function of look than (3), which, in turn cannot be omitted as a surplus element over the propositional, target-oriented meaning of $\mathrm{p}$.

The 'surplus approach' draws especially from politeness theory and reciprocity in social psychology and pragmatics (cf. Kasper 1990; Culpeper 2011; Author et al. 2017). It is based on the premise that the problematisation of another agent's 'face' is cognitively more demanding than mere

\footnotetext{
${ }^{2}$ It is acknowledged that redundant language is of prime importance in an analysis of the performance of speech events and social awareness of ritualised behaviour (cf. Rizza 2009)
} 
action-oriented communication, as it is shown that thinking about other people mental states requires more time and executive functioning both in children and adults (e.g. German \& Hehman 2006; Apperly 2008). Addressed from a usage-based angle, the surplus approach needs to be necessarily corpus-driven, based on data converging from ontogenetic development and language change. It is centred on co-actionally 'redundant' constructions or syntactical ordering that start being mastered at a comparatively later stage of first language acquisition with the overt purpose of accounting for (an-)other mind(s). It tackles operationally the gradient relationship between 'interested' intentions and sedimentation (cf. Husserl [1936]1970; Zlatev \& Blomberg 2016) of linguistic knowledge, which in turn, allows to overtly codify the awareness of other individuals' stances, emotions and beliefs. The latter are addressed as ad-hoc strategies or constructions that are cognitively more demanding than ones that are merely centred on co-actional, speaker-oriented endeavour.

For instance, in the case of (1) actually and I wouldn't mind it staying are both a codified surplus over the same propositional, per-locutionary oriented meaning (cf. Searle 1969; Searle \& Vanderveken, 1985) that could be communicated with less cognitive processing (cf. Grice 1976 maxim of quantity; Sperber \& Wilson 1995; Wilson \& Sperber 2004: 609): leave it open; don't close $i t$; no or any other unmarked formulae directly encoding a directive speech act at the co-actional level with a clear per-locutionary effect: window still open. Developmental stages of 'thinking of thought' are characterised by the awareness that one's individual desires may be a possible threat for one's own and others' face needs (e.g. Brown \& Levinson 1987; Yu 1997). The social clash between interested 'language-for action' and the awareness of $\mathrm{Ad} / \mathrm{r}$ 's face is the dimension where ToM comes into play as a gradient mechanism of 'codified awareness of the other(s)'. In this sense, the surplus element of an intersubjective construction needs to be one that $\mathrm{Ad} / \mathrm{r}$ can identify as additional effort over meaning that exclusively codifies 'subjective', viz. merely speaker oriented intentions.

As pointed out in the previous sections, a directive speech act such as leave it open is beyond doubt based on joint attention, yet it still lacks a 'constructional' surplus that is necessary to overtly problematise the online awareness of $\mathrm{Ad} / \mathrm{r}$ or $3 \mathrm{rdP}$ 's mind(s). This is clearly not to say that here $\mathrm{Sp} / \mathrm{w}$ would be necessarily showing a deficient ToM ability. Rather, that from an operational point of view, there would be no overt indication of communicated intersubjective awareness being accountable in a corpus-based analysis (cf. McCafferty 1998; Mori \& Hayashi 2006 for alternative embodied, nonverbal accounts of intersubjective coordination). 


\section{From co-actional joint-attention to extended intersubjectification}

This section aims at putting the 'surplus-approach' into practise and to crucially combine ontogenetic and diachronic data to identify intersubjectivity as an overt effort triggered by the awareness of an(other) $\operatorname{mind}(\mathrm{s})$.

\subsection{The case of this, that and such}

In recent accounts, so-called identifying and intensifying usages of the pre-nominal such have been discussed diachronically, especially in connection with the intersubjective dimension. Ghesquiere \& Van de Velde 2011 (2011: 771) suggest that attested usages at the beginning of the cline of such are characterised by a textual-identifying function. They propose an intersubjective interpretation based on the argument that such semantically contributes to establish joint attention with $\mathrm{Ad} / \mathrm{r}$. Similar identifying functions of such are still widely in use in Present-day English as in the example below:

(5) The teaching of mixed-ability classes becoming the norm must be avoided at all costs. Very marginal benefits come from such teaching and the system must allow for some form of streaming.

(CB Times $1990-1996)$

The identifying function in (5) helps $\mathrm{Ad} / \mathrm{r}$ to determine the type of which the NP referent is an instance (e.g. Carlson 1978: 219; Ghesquiere \& Van de Velde 2011: 772). Identifying usages of such thus set up phoric relations in the discourse connecting the NP referent with the referent of another preceding (anaphoric) or following (cataphoric) NP.

Drawing on Bolinger's (1972) hypothesis, Ghesquiere \& Van de Velde (2011) provide corpus-based data from Old up to Present-day English, arguing for a new intensifying function of such (hereby, INT-such). Despite not providing diachronic cases of intensifying usages, they illustrate the mismatch with the identifying such synchronically:

(6) It used to be such a thrill when you saw English cars on the road had to negotiate a serious low point in his training career.

(CB Times $1990-1996)$

(7) It's not just that it played such an important part in my life, but the fact that the 
nurses and doctors there do such terrific work.

(CB Times $1990-1996)$

(Ghesquiere \& Van de Velde 2011: 783)

Examples (6-7) above are not phoric as they do not encode reference to either a preceding or ensuing element of the discourse. They are rather intensifying (hereby INT-such) as they heighten "the degree of a certain evaluative or scalar notion inherent in the modified element" (cf. Ibid: 7682). The authors therefore suggest that the INT-Such encodes a subjective meaning and thus constitutes a counterexample to the unidirectional cline of change towards intersubjectivity proposed by Traugott (e.g. 2010: 34). The diachronic formation of new polysemies is especially relevant for the present study, as they constitute 'meaning potentials' (Norén, K. \& Linell 2007; Linell \& Lindstrom 2016: 125) that can be associated with a certain word or construction. Inspired by the call for a new 'applied' turn of language emergence and language change (cf. Ellis \& Larsen-Freeman 2006; MacWhinney 2006), a crucial hypothesis of the present approach is the idea that intersubjective polysemies of the same construction or lexeme are spontaneously mastered at comparatively later stages of ontogenetic development. This is clearly not to say that the same clines of change that we can observe diachronically within a speech community are replicated unidirectionally throughout the process of first language acquisition of a single child. More reasonably, I propose that overtly intersubjectified functions of the same linguistic form are mastered only after stage of ontogenetic development where the child is able to intentionally rely on a ToM ability.

\subsection{An operationalization of the 'hybrid' approach to intersubjectivity}

While it has been acknowledged that phonological reduction and morphosyntactic change are not reliable criteria for comparing diachronic and ontogenetic change, yet striking similarities have been observed for what concerns unidirectional patterns of semantic-pragmatic reanalysis (Diessel 2011), as they involve similar mechanisms of change (Ziegler 1997) or similar adaptive behaviours (Givón 2009). Crucially, contemporary research on intersubjectification can be informed by experimental findings about the ontogeny of ToM and help formulate a gradient, more elaborate redefinition of the intersubjective paradigm. ToM is today often argued to become more sophisticated through middle childhood and adolescence (Epley et al. 2004; Dumontheil et al. 2010), and in most recent accounts is viewed as a gradient ability that keeps developing far beyond early ontogeny up to adulthood (cf. Apperly 2013). Correspondingly, there appears to be a significant correlation between competence of everyday mindful conversational skills and in-lab ToM performance (cf. De Rosnay et al. 2014: 1184). 
The gradient account of intersubjectivity proposed here aims at capturing usage-based tendencies towards increasing complex verbalisation of ToM mechanisms converging from language change and ontogenetic development. The English section ranging from 0 up to 6-year-olds of the CHILDES database comprises 4,689,215 tokens. Among those, such occurs 85 times (2.88 per milion words, henceforth pmw). This number is significantly lower than other deictic markers with an identifying function such as this (63,225 times; 2,144.60 pmw) or that (89,276 times; 3,028.30 pmw), both of which semantically underpin joint attention (e.g. Diessel 2006). From the CHILDES, this and that are first used by the age of 1 year and 8 months (e.g. corpus Bates/keith20, hereby abbreviated as $1 ; 8$ ), while only one identifying usage of such (therefore ID-such) has been found in spontaneous interaction before the age of 4 (3 years 11 months, hereby abbreviated as 3;11). On the other hand, intensifying functions of such (from now on given as INT-such) are already attested by the age of 2 $(2 ; 2)$. Below are given three examples of this tendency:

(8) MOT: Try right there ! try right there ! Want to stack them for me ?

CHI: That baby!

MOT: Oh. Did you say baby?

CHILDES/Bates/Betty20

Age: $1 ; 8$

(9) CHI: She mustn't jump up on the cot. She might break the cot. Helen's got such a bad cold. Get a bite off this one, too.

CHILDES/Haggerty

Age: $2 ; 7$

(10) CHI: I don't think there any are witches.

FAT: Why?

CHI: Because I've never seen such a witch.

CHILDES/Macwhinney/47b2 Age: $3 ; 11$

From the above, it clearly appears that joint attention is already encoded with that by a 1 year old child in (8). The earliest case of INT-such in (9) is uttered by the age of 2. On the other hand, the first instance of an ID-such is the one in (10) and it is uttered almost at the age of 4. Table 1 below reports the raw frequency of all the instances where such is found up to the end of the third year of age (0-3 subcorpus counts 3,525,724 words): 


\begin{tabular}{llllll}
\hline & $2 ; 2-2 ; 7$ & $2 ; 8-3$ & $3 ; 1-3 ; 7$ & $3 ; 9-3 ; 11$ & Tot \\
\hline Intensifying & 5 & 8 & 2 & 2 & 17 \\
Identifying & 0 & 0 & 0 & 4 & 4 \\
Singing/imitating/reported & 3 & 2 & 4 & 3 & 12 \\
\hline Tot & 8 & 10 & 6 & 9 & 33
\end{tabular}

Table 1.

Usages of such from the CHLDES up to the end of the 3rd year of age

Table 1 above includes intensifying and identifying usages together with a third category where children are either singing an already known song or imitating what their interlocutors are saying. In the same group are also included instances that children 'allegedly' uttered, yet not directly recorded during their conversations. In all cases above, children are not spontaneously or independently making use of such and will not be considered as reliable instances of use. Despite the relative low frequency of such in the 0-3 span of the CHILDES, 2 facts clearly emerge from table 1:

1. Children seem to be able to master intensifying usages of such since early stages of $2 \mathrm{Y}^{3}$.

2. Children do not spontaneously use such with an identifying function before approaching $4 \mathrm{Y}$.

Interestingly, from $4 \mathrm{Y}$ up to $6 \mathrm{Y}$, such then occurs 52 times $(1.80 \mathrm{pmw})$ with a much more even distribution between intensifying and identifying usages (4-6 subcorpus counts 1,442,956 words):

\begin{tabular}{lllll}
\hline & $4-4 ; 11$ & $5-5 ; 11$ & $6-6 ; 11$ & Tot \\
\hline Intensifying & 19 & 5 & 6 & 30 \\
Identifying & 15 & 4 & 2 & 21 \\
Singing/imitating/reported & 0 & 0 & 1 & 1 \\
\hline Tot & 34 & 9 & 9 & 52
\end{tabular}

Table 2.

Usages of such from the CHLDES from the 4th up to the end of the 6th year of age

\footnotetext{
${ }^{3}$ Year 2.
} 
What is specifically distinctive of this data-set is the increased frequency of ID-such, which after being normalised across the two subcorpora, results statistically significant across the 0-3 and the 46 periods (Fisher exact test $\mathrm{p}<0.005$ ). Ontogenetic data from table 1 and 2 seems to support Ghesquiere \& Van de Velde's intersubjective classification of ID-such (as it is not mastered before the end of the 3rd year of age), while intensifying usages encode a comparably more subjective, speaker-centred meaning (at the beginning of $2 \mathrm{Y}$, children already seem to use it spontaneously). This fact may be relevant for both synchronic and diachronic research of intersubjectivity as it supports the idea of patterns of usage moving against the unidirectional cline of change towards intersubjectification proposed by Traugott (e.g. 2010).

However, what still needs to be clarified is the argument for considering ID-such as an intersubjective construction 'per se'. In fact, despite what is suggested by Diessel (2006) and Ghesquiere \& Van de Velde (2011), joint attention alone cannot be a factor, as deictic functions of this and that are attested to be acquired towards the end of $1 \mathrm{Y}$. What is now at stake is thus the distinctive intersubjective construal (if any) that children need to master at the end of $3 \mathrm{Y}$ in order to spontaneously make use of ID-such. The main aim of the following subsection is to address this research question both on a methodological and a theoretical level.

\subsection{Inferential assumptions about the social persona's mind}

Spoken language among adults is characterised by a significantly more frequent usage of ID-such in comparison with INT-such. Out of a random sample of 100 collocates of such from the dialogicspoken section of the BNC only 29 occurrences are of the INT-such type, while 71 belong to the IDsuch category. From early childhood towards adulthood there seems to be an increasing tendency of such being used with an identifying function. As mentioned earlier, ID-such is inherently phoric, as it can refer to a previous or forthcoming element of the discourse. It expresses a categorial meaning, which can alternatively expressed with the construct [the kind of $\mathrm{NP}$ (that) $\left.\mathrm{P}^{4}\right]$. The latter occurs only 3 times in the $0-3$ section of the CHILDES:

(11) MOT: That's gonna be very funny tea.

CHI: That's the kind of tea that I'm making for them.

MOT: (Be)cause they like that kind of tea.

\footnotetext{
${ }^{4}$ Proposition.
} 
Age: $3 ; 3$

(12) FAT: Whoops

CHI: This is the kind of mustard that you like.

FAT: Really?

CHILDES/Gleason/Isadora

Age: $3 ; 7$

(13) MOT: What's that ?

CHI: That's the kind of food that they eat.

MOT: You mean pancakes?

CHILDES/Suppes/Nina55

Age: $3 ; 8$

All the three examples above occur during the third year of age. In each case [the kind of NP] always has to do with inferences of what $\mathrm{Ad} / \mathrm{r}$ or a $3 \mathrm{rdP}$ may 'like'. It defines a category that is informed by a mindreading mechanism, i.e. inferring about what someone specific likes, drinks eats. The frequency of the same construction then rises sharply up to 143 collocates during the 4-6 year span, significantly shifting from $0.85 \mathrm{pmw}$ in the $0-3 \mathrm{Y}$ subcorpus to $99.1 \mathrm{pmw}$ in the 4-6Y subcorpus.

In figures 1 and 2 below are given respectively:

- the pmw frequencies of this and that in the two subcorpora 0-3Y and 4-6Y

- the pmw frequencies of INT-such, ID-such and [the kind of NP] in the two subcorpora $0-3 \mathrm{Y}$ and 4-6Y:

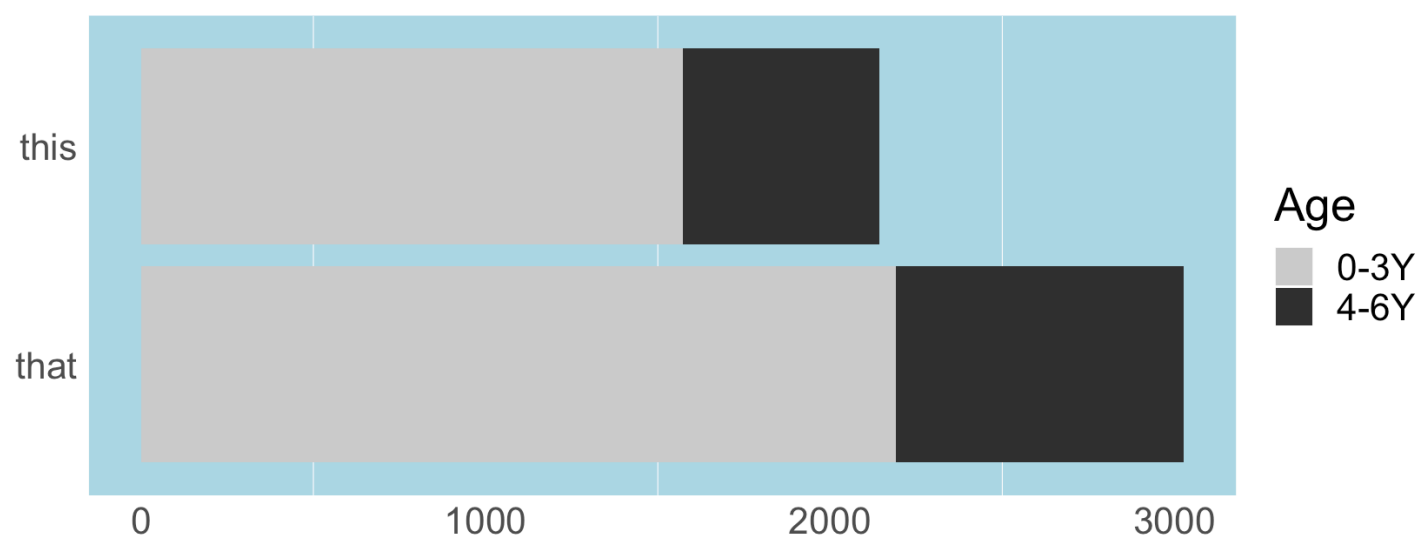

Figure 1.

Normalised frequencies of this and that in the 0-3Y and 4-6Y sections from the CHILDES 


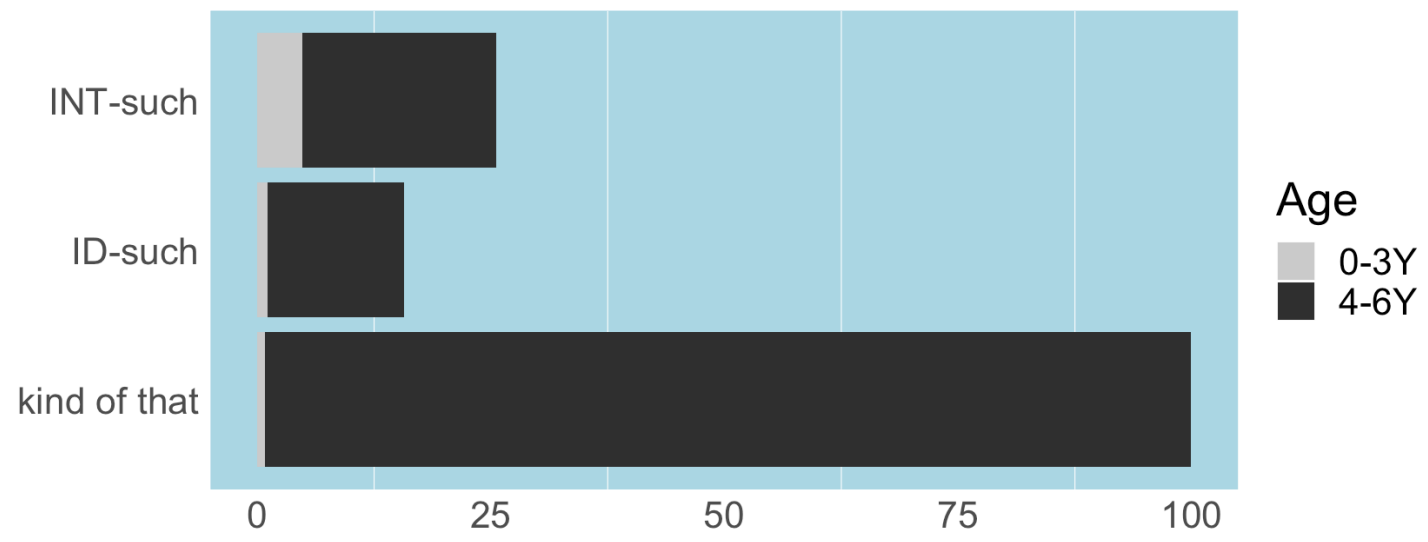

Figure 2.

Normalised frequencies of INT-such, ID-such and [the kind of NP] in the 0-3Y and 4-6Y sections from the CHILDES

While comparing figure 1 and 2 above, it is possible to observe a reverse tendency: in figure 1 the pmw frequency of co-actional identifiers this and that dramatically decreases from 0-3Y to 4-6Y, whereas in figure 2 the opposite occurs for INT-such, ID-such and [the kind of NP]. Most intriguingly, the mismatch across the two subcorpora between INT-such and the latter two constructions (ID-such and [the kind of NP) is statistically significant (Fischer Exact Test, p $0<0.5$ ). This means that, across $3 \mathrm{Y}$ and $4 \mathrm{Y}$, the process of acquisition of ID-such and [the kind of NP] seems to both start and develop at an exceptionally rapid rate, viz. significantly faster than the acquisition of INT-such.

Once again, concerning ID-such and [the kind of NP] there seems to be a specific element that contributes to the way children merge inferential classifications and ToM mechanisms. In fact, both ID-such and above usages of [the kind of NP] involve generalised instantiations, viz. abstractions "involving instances of a given type" (Langacker 2009: 9) allowing users to establish mental contact "through the mediation of fictive or virtual entities conjured up for that purpose" (Langacker 2005: 170). Figure 3 below illustrates the schematic relationship between 'experiential' instances of an entity (X1, X2, X3), which are then projected into a categorical space, where the same entity is then construed as a generalised type $(\mathrm{X})$ :

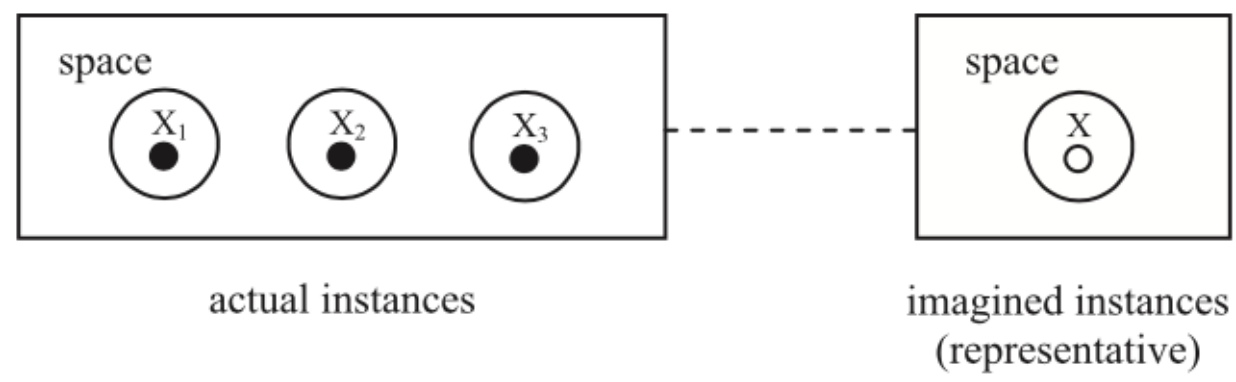

Figure 3. 
Generalised instantiations of the kind given in (11-12-13) all inherently involve both the effort to infer another mind's state together with the awareness of an abstract 3rd party (3rdP) functioning as a social persona who could confirm the generalised nature of the referent. In this sense, the 'extended' awareness of $3 \mathrm{rdP}$ is the semantic element that is crucially missing in deictic constructions that simply encode joint attention such as this or that. At early stages of ontogeny, meanings of deictics are inherently co-actional, in the sense that they require attention of an interlocutor to pursue a speakeroriented project, e.g. reaching a toy, not wanting the milk and so on. Conversely, it is reasonable to assume that ID-such or [the kind of NP] are acquired later for they involve a categorisation process underpinning a social meaning and and flexible reasoning about new mental models (cf. de Ruiter et al. 2018). They problematise a particular mental state based on the assumption of what a general one (3rdP) would agree upon.

In cases of ID-such and [the kind of NP] given below, a subjective proposition $\mathrm{p}$, a 3rdPoriented proposition $\mathrm{Q}$ together with an $\mathrm{Ad} / \mathrm{r}$-oriented proposition $\mathrm{R}$ are at issue:

(14) CHI: Aren't they long nails ?

FAT: Yeah.

CHI: What do why do they have to have such long nails?

FAT: I don't know.

Childes/Macwhinney/79b1

Age: 4;9

P: I think the nails we are referring to are long. (Subj)

$\mathrm{Q}$ : I know 3rdP would agree that those nails are long. (3rdP)

$\mathrm{R}$ : I expect $\mathrm{Ad} / \mathrm{r}$ to be aware of what I and $3 \mathrm{rdP}$ think. $(\mathrm{Ad} / \mathrm{r})$

(15) CHIa: That's different.

CHIb: Maybe it was the kind of mud that sticks to you.

CHIa: No it doesn't. Just stays on your clothes.

Childes/Carterette/First

Age: 6

P: I suspect the mud we are referring to is sticky. (Subj)

$\mathrm{Q}$ : I know 3rdP experienced something similar before. (3rdP)

$\mathrm{R}$ : I expect $\mathrm{Ad} / \mathrm{r}$ to have experienced what I and $3 \mathrm{rdP}$ did. $(\mathrm{Ad} / \mathrm{r})$ 
As a generalised instantiation, the choice of ID-such in the examples above encodes a 'surplus' of intersubjective awareness over mere co-actional choices of this/that. In fact, while such semantically entails the identifying meaning of this/that, however it cannot simply encode joint attention without entailing the extended problematisation of $3 \mathrm{rdP}$ :

(16) MOT: I didn't xxx there's a bug. What bug?

CHI: There's no such thing as it went that way.

Childes/Hall/Mig

Age: $4 ; 6$

a. *CHI: there's no such thing as it went *such way.

(17) MOT: What are you doing ?

CHI: Sleepin(g) on that chair.

Childes/Bates/George28

Age: 2;4

a. *CHI: Sleepin $(\mathrm{g})$ on *such chair.

(18) CHI: Look at this book Cathy!

CHI: Look!-

INV: Ah! Oh that's a really good one.

Childes/Belfast/Barb08

Age: $3 ; 2$

a. *CHI: Look at *such book Cathy!

Examples (16-17-18) above illustrate that ID-such cannot replace deictic meanings merely encoding co-actional joint attention among interlocutors. In fact, in addition to its identifying function, it IDsuch semantically encodes a ToM process of categorisation based on what CHI expects 3rdP's mind would support or confirm, thus encoding extended intersubjectivity (E-I), as illustrated symbolically in the diagram below: 


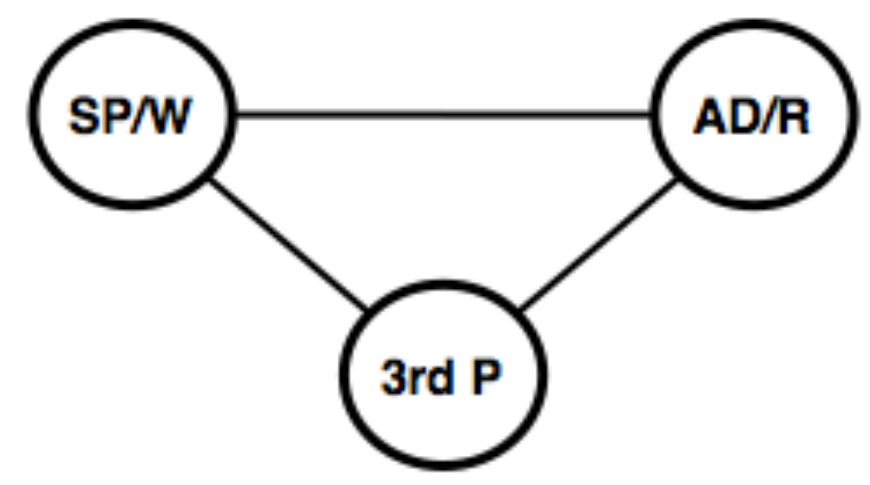

Figure 4.

Extended Intersubjectivity (cf. Author, 2013, 2015, 2016, 2017a, 2017b)

Figure 4 indicates that, beyond the awareness of a specific interlocutor ( $\mathrm{Ad} / \mathrm{r})$, E-I constructions require the additional construal of a general 3rdP as a social bearer of the utterance, viz. a general persona who could confirm Sp/w's proposition. The semantic mismatch between co-actional joint attention and inferential assumptions of extended intersubjectivity is what may determine the abrupt propagation of ID-such and [the kind of NP (that) P] constructions towards the end of the 0-3Y and the whole of 4-6Y subcorpora.

\subsection{Pre-nominal identifiers from 0 to 9 years of age}

Increasing identifying strategies based on extended intersubjectivity require a process of categorisation. The focus of this section is thus on the mechanisms that lead to the usage-based increase of constructions like ID-such or [the kind of NP] at a relatively late stage of ontogenetic development. Similarly, it is important to shed light on why this tendency significantly correlates with the sharp decrease of use of the predominantly co-actional deictics this/that. This can be addressed with a distinctive collexeme analysis (cf. Gries and Stefanowitsch 2004a; Hilpert 2006) and a behavioural profile account (e.g. Gries 2010; Gries \& Otani 2010; Jansegers \& Gries 2017) of all variables intervening in the codification extended intersubjectivity (this will be discussed in 5.6).

Distinctive collexeme analysis draws on collostructional analysis (e.g. Stefanowitch \& Gries 2003; Gries 2015). It is based on a bidirectional statistical independence tests (i.e. the Fisher exact test), which shows whether the co-occurrence frequency is significantly different from what one could expect under the assumption of no association (the null hypothesis). It can be used to compare the distinctive attraction among two (or more) competitive lexemes (hereby defined as collexemes) with a construction (or collostruct) in different periods of time. While this method is often used in historical linguistics, this study extends its application to ontogenetic data. While simple chi-square tests or 
logistic regression models could equally be applied to the present data, collostructional analysis is specifically centred on the potential attraction between the internal constituents of a construction and the construction itself. This model is theoretically more compatible with the usage-based hypothesis that 'older' children would show new ToM abilities by increasingly associating such with identifying constructions underpinning extended-intersubjectivity (E-I). This tendency will be compared with other identifying (this, that) and intensifying (very) constructions that do not include an E-I meaning potential.

First, it is necessary capture the degree of attraction or repulsion of the collexeme [this] within the collostruct [this NP] as opposed to [ANY-OTHER-ID ${ }^{5}$ (given as other in table 6) appearing in the [ANY-OTHER-ID NP] collostruct in each periodised sub-corpus.

\begin{tabular}{rrrllll}
\hline & obs freq this & obs freq other & exp freq this & exp freq other & pref. occ & coll. strength \\
\hline $0-3$ & 9733 & 129580 & 9065.40 & 130247.59 & this & 32.50 \\
$4-6$ & 4037 & 61144 & 4241.47 & 60939.52 & other & 4.26 \\
$7-9$ & 707 & 17275 & 1170.12 & 16811.87 & other & 54.32
\end{tabular}

Table 6.

Distinctive collexeme analysis of $[$ this $]$ vs $[\text { ANY-OTHER-ID }]^{6}$

In table 6 above the two competitive variables [this] vs [ANY-OTHER-ID] have been measured through the 3 subcorpora $0-3,4-6$ and 7-9. With the premise that in distinctive collexeme analysis collostructional strength values that are higher than 1.3 are considered significant, we con observe a distinctively high value (32.50) of this as a collexeme of the [ID NP] collostruct during the 0-3 timespan. Crucially, after the fourth year of age, the 'competitor' [ANY-OTHER-ID] is then significantly attracted to the [ID NP] collostruct. This value then increases dramatically during the 7-9 time-span (54.32). Here, it is fundamental to note the degree to which the distinctive use of this in identifying constructions is then progressively counterbalanced by alternative pre-nominal identifiers. This fact seems to further illustrate an increased cognitive complexity of the [ID NP] schematic construction as such, rather than a more diverse choice of lexical items which could fill the [ID] node (i.e. the logdice vaules of pre-nominal identifiers display similar lexical items in the three subcorpora). An

\footnotetext{
${ }^{5}$ Identifier.

${ }^{6}$ As for the output from R, in table 8 are given the observed frequencies (obs freq) of the two variables, their expected frequencies (exp freq), the preferred occurrence from one time-span to another and the collostructional strength for each period.
} 
even more striking tendency (0-3: that; 4-6: other; 7-9: other) emerges from the co-actional that as a collexeme of [ID NP]:

\begin{tabular}{rrrllll}
\hline & obs freq that & obs freq other & exp freq that & exp freq other & pref. occ & coll. strength \\
\hline $0-3$ & 11452 & 127861 & 9928.29 & 129384.70 & that & 153.93 \\
$4-6$ & 3853 & 61328 & 4645.19 & 60535.80 & other & 47.71 \\
$7-9$ & 550 & 17432 & 1281.50 & 16700.49 & other & 132.49
\end{tabular}

Table 7.

Distinctive collexeme analysis of [that NP] vs [ANY-OTHER-IDENTIFIER NP]

While during the $0-3$ period that is distinctively attracted to [ID NP] to an extremely large degree of collostructional strength (153.93), from the 4-6 period on, [ANY-OTHER-ID] is distinctively preferred as a collexeme ranging from 47.71 (4-6) to a striking 132.59 (7-9).

\section{5 'Ad-hoc' generalizations and extended intersubjectivity: A collostructional account}

This section is concerned with the usage-based increase of identifying pre-nominal constructions of generalised instantiation: [ID-such NP] [the kind of NP that $\mathrm{P}$ ] in comparison with any other identifying function throughout the first 9 years of the CHILDES. This is to be compared with distinctively subjective pre-nominal intensifying constructions [INT-such NP], [a very NP]. In so doing, it should be possible to contrast the usage of predominantly subjective [INT NP] schemas (where INT corresponds to an intensifier) to comparably more intersubjective [3rdp-ID NP] ones (where 3rdp-ID corresponds to a generalising identifier construing Sp/w's inference based on extended intersubjectivity (E-I), e.g. generalising functions such as: the kind of mud that sticks to you; there is no such thing as witches).

In tables 8 and 9 below is given the distinctive collexeme analysis of respectively [INT-such $\mathrm{NP}]$ and $[a$ very $\mathrm{NP}]$ as opposed to any other $[a(n) \operatorname{AdjP~NP}]$ construction occurring without a preadjectival intensifier:

\begin{tabular}{lrrllll}
\hline & obs freq such & obs freq other & exp freq such & exp freq other & pref. occ & coll. strength \\
\hline $0-3$ & 17 & 7725 & 18.49 & 4787.51 & other & 3.53 \\
$4-6$ & 30 & 4776 & 18.52 & 4787.47 & such & 3.04 \\
$7-9$ & 5 & 965 & 3.73 & 966.27 & such & 0.50
\end{tabular}


Table 8 .

Distinctive collexeme analysis of [INT-such NP] vs [a(n) AdjP NP]

\begin{tabular}{rrrllll}
\hline & obs freq very & obs freq other & exp freq very & exp freq other & pref. occ & coll. strength \\
\hline $0-3$ & 3116 & 7803 & 2068.77 & 8850.23 & very & INFINITE \\
$4-6$ & 56 & 4866 & 932.55 & 3989.45 & other & INFINITE \\
$7-9$ & 15 & 965 & 185.68 & 794.32 & other & 68.7
\end{tabular}

Table 9.

Distinctive collexeme analysis of $[a$ very NP] vs $[a(n)$ AdjP NP $]$

From both tables above there seem not be any correlation between age-beyond- 4 and marked use of INT-such or very as intensifiers of indexical $[a(n)$ Ajd NP] constructions. In fact, the collostructional strength of INT-such in the 7-9 sub-corpus is below 1.30103, thus not significant ( $p>0.5)$. Similarly, the overall computation of the collexeme very shows a significant decrease of intensifying usages over time. Simply put, the collostructional attraction of very to indexical [a (n) Adj NP] collostructs drops significantly starting from the 4 th year of age.

More consistent is the ontogenetic trend of both [ID-such] and [the kind of NP that] as they both show a distinctively significant attraction to the collostruct [ID NP] only after the fourth year of age:

\begin{tabular}{lrrllll}
\hline & obs freq such & obs freq other & exp freq such & exp freq other & pref. occ & coll. strength \\
\hline $0-3$ & 4 & 1074484 & 27.84 & 1074460.16 & other & 25.42 \\
$4-6$ & 21 & 65181 & 1.69 & 65200.31 & such & 19.30 \\
$7-9$ & 5 & 17982 & 0.47 & 17986.53 & such & 4.03
\end{tabular}

Table 10.

Distinctive collexeme analysis of [ID-such] vs [ANY-OTHER-ID]

\begin{tabular}{lrrllll}
\hline & obs freq the kind & obs freq other & exp freq the kind & exp freq other & pref. occ & coll. strength \\
\hline $0-3$ & 3 & 1074485 & 13.92 & 1074474.08 & other & 11.15 \\
$4-6$ & 8 & 65194 & 0.84 & 65201.16 & the kind & 6.34 \\
$7-9$ & 4 & 17983 & 0.23 & 17986.77 & the $k$ kind & 4.16
\end{tabular}


Table 11.

Distinctive collexeme analysis of [the kind of NP that] vs [ANY-OTHER-ID]

This point is important to show that there seems to be a direct correspondence between children's ability to make independent, 'ad-hoc' and context-bound generalisations and ToM as a mechanism going beyond simple co-actional engagement. This tendency is consistent throughout the 4-9 yearold time span and significantly not at play before the 4th year of age. In line with this trend, it is possible to observe a significant decrease of more subject-oriented intensifying usages intersecting with indefinite indexicality $[a(n)$ INT NP].

\section{6 'Ad-hoc' generalisations and extended intersubjectivity: A behavioural profile account}

While the distinctive collexeme analysis in 5.5 compares intensifying and identifying usages of such across the first 9 years of age in a discrete manner, this section gives a more holistic account of the intersection of the ability of making generalised instantiations and ontogenetic intersubjectification. To do so, it is necessary to control variables that contribute to the codification of extended intersubjective meanings: co-actionality and abstraction (viz. whether the speech event occurs in the form of a physical co-action, whether the referent is visually present during the speech event), complexity (how many verbs are included in the construction and the verb types that are present in the main clause), reference (specific vs generic) and additional intersubjective and meta-discursive components (the number of personas being accounted for in the utterance and whether some additional discourse marker collocates with the construction).

All these variables have been included in a behavioural profile analysis (BPA) (e.g. Gries 2010; Gries \& Otani 2010; Jansegers \& Gries 2017) of the constructions such, this, that, [kind of NP that $]$ and very in in order to find clusterings of resemblance through the child's ontogenetic development. The object of this enquiry are three schematic functions: co-actional identification (this, that), intensification (very, INT-such) and E-I identification (the kind of NP, and ID-such).

BPA allows allows for the inclusion of different forms of constructions as well as very many different kinds of co-occurrence information (morphological, syntactic, semantic, functional, etc.). In addition, it integrates different levels of statistical analysis, ranging from simple frequencies/percentages via correlations up to hierarchical cluster analyses and, by way of extension, logistic regression compatible with exemplar-based models (Gries 2010: 325). What distinguishes this method from traditional corpus-based analysis, is that it goes beyond the mere comparison of frequencies across corpora/data-sets. Rather, it is designed to identify holistic patterns of context, 
meaning and form deriving from clusterings that are based on 'behavioural' similarity of linguistic forms. The focus of the present case-study is on data-driven convergences of meaning potentials of such at different stages of ontogenetic development. More crucially, it aims to show whether the usage of such becomes increasingly similar to [the kind of NP] and comparatively different from coactional functions of this and that.

The annotation of all constructions exceeding 200 occurrences in each corpus (e.g. this, that, very) was the result of a three-step process: first, the annotation of the profiles of a 200 collocates random sample, and subsequently the multiplication of the 200 annotated strings until reaching the overall frequency of that particular construction in the corpus (e.g. 16,831 for this in the 4-6Y section, with the remaining 84 occurrences being obtained after a second random-sampling from the 200 annotated occurrences). Finally, despite normalisation is not generally required in BPA analysis, due to the considerably different size of the three subcorpora of the CHILDES and the above sampling technique, all annotated profiles have been normalised using the first sub-corpus 0-3Y as a reference (the object of normalisation were the observations rather than the frequencies of the lexemes). Table 12 below provides the entry of one profile (this case is such) out of 42319 annotated entries relative to the 4-6Y period.

\begin{tabular}{|l|l|l|l|l|l|l|l|}
\hline ID-tag & sight & verb-type & co-action & verbs & reference & personas & DM \\
\hline such & sight & be & abstract & 1 & generic & 2 & 0 \\
\hline
\end{tabular}

Table 12.

Input for BP analysis of such, this, that, very and [the kind of NP that] for each age-span

Below is given a comparison between the cluster analysis of respectively all annotated profiles for 0$3 \mathrm{Y}$ and 7-9Y age-spans. Silhouette widths values compare within and between cluster similarities: "the higher an average silhouette width for a particular cluster solution, the better that cluster solution" (cf. Gries 2010: 332). 


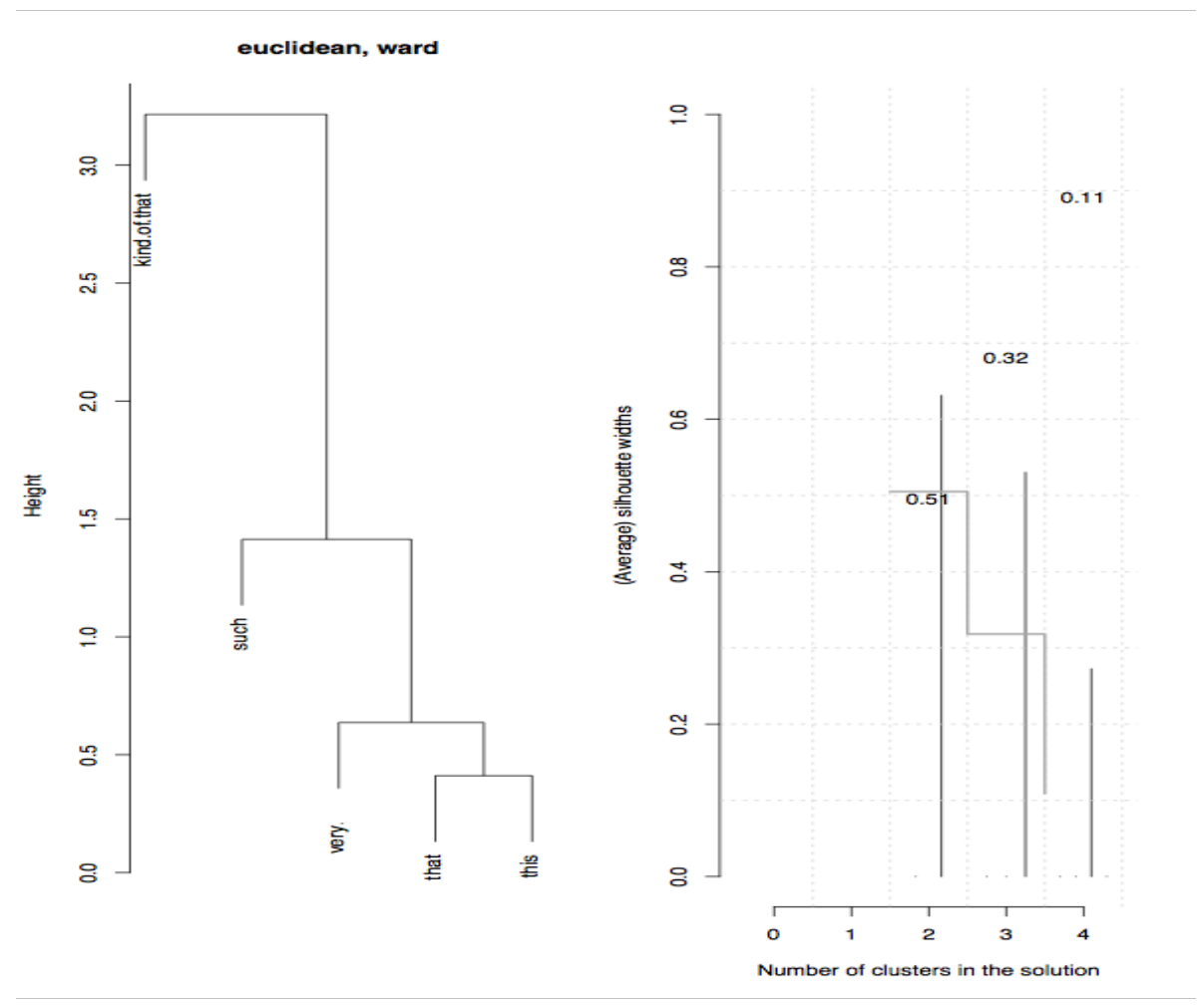

Figure 6.

Dendogram resulting from the BP analysis for the $0-3 \mathrm{Y}$ age-span

The silhouette widths on the y-axis are plotted against all possible numbers of clusters for 5 elements on the $\mathrm{x}$-axis. The plot on the right hand-side includes black vertical lines and a grey step function for the averages, viz. the higher the value (0.51), the more accurate the number of clusters, which in this case is 2. Interestingly, the distance between [kind of NP that] (first cluster) is the greatest from mostly co-actional identifiers this and that, which are part of the second cluster, also including very and such. At this stage such is in an intermediate position between [kind of NP that] and [very AP]. 


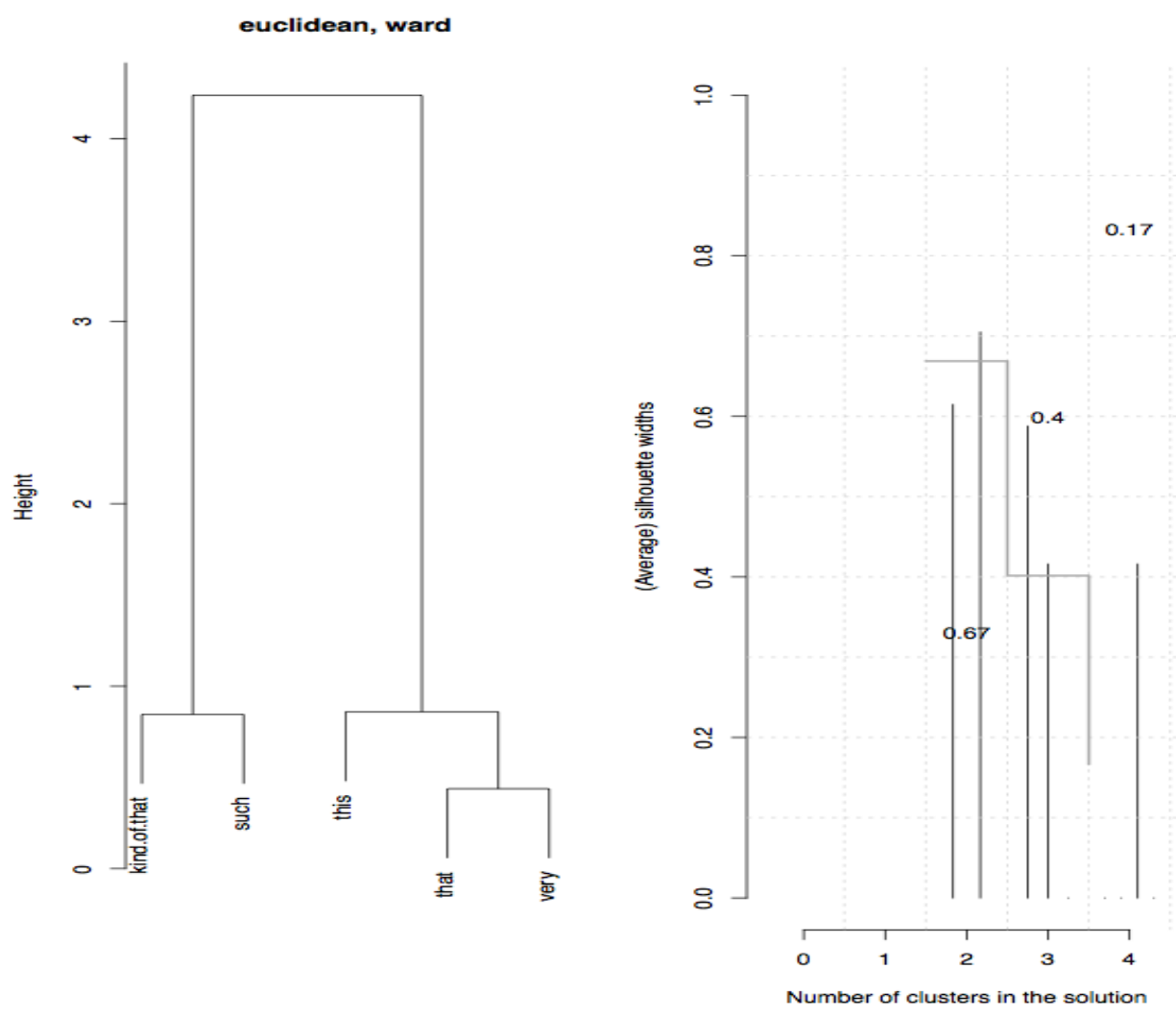

Figure 7.

Dendogram resulting from the BP analysis for the 7-9Y age-span

In the 7-9Y age-span such directly forms a separate cluster with [kind of NP] suggesting a higher behavioural resemblance with constructions that are specifically aimed at construing generalised instantiations.

The BP analysis across all three year-spans is best represented through a multidimensional scaling algorithm (MDS) which transforms a distance matrix into a set of coordinates for each profile (e.g. Jansegers \& Gries 2017): 


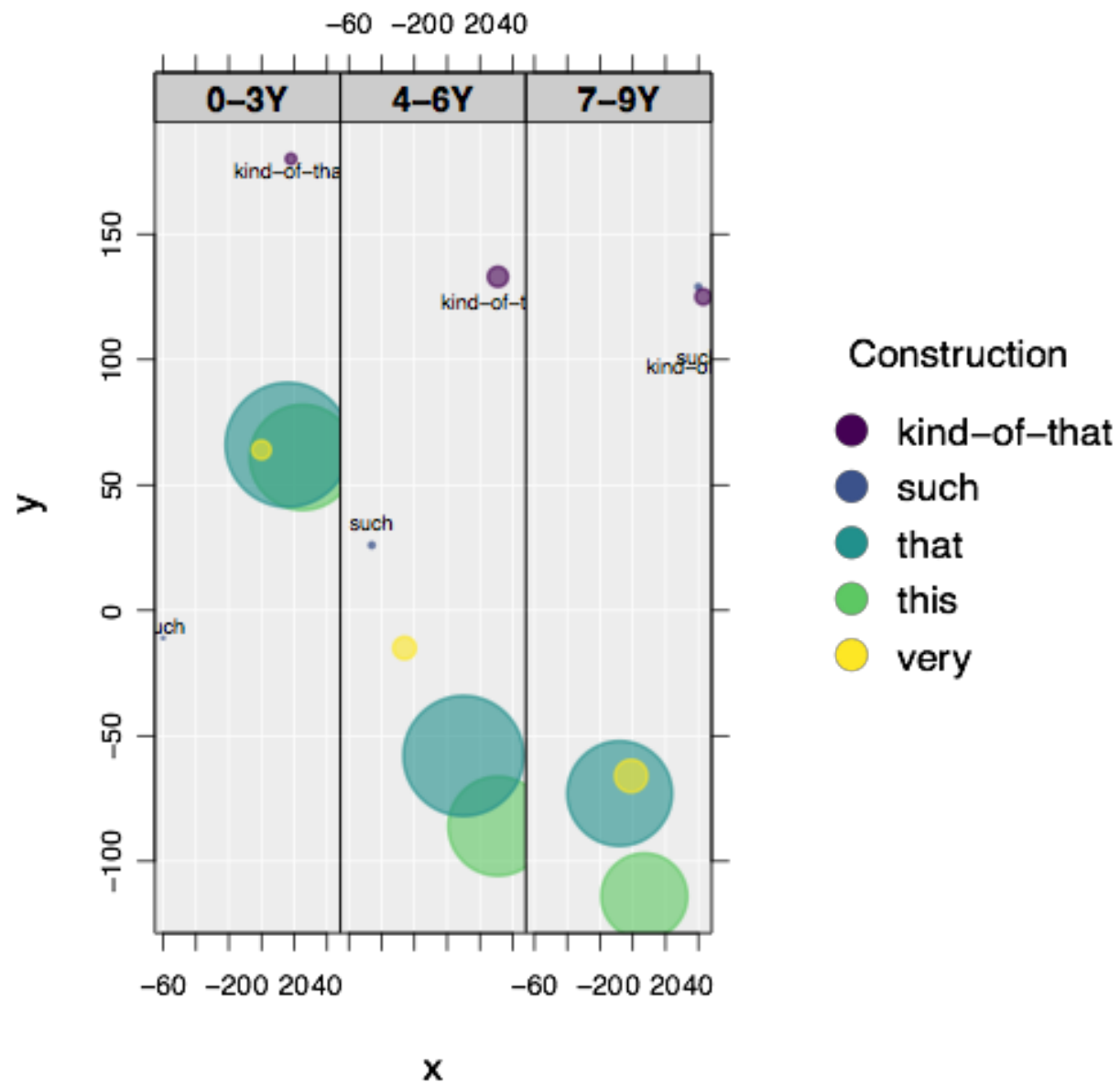

Figure 8.

Multidimensional scaling of the BP similarity of the 5 constructions across the 3 age-spans

The bubble-chart above accounts for degree of profile-resemblance ( $\mathrm{x}$ and y axes) and normalised frequency (expressed by the bubble-size) across the three age-spans 0-3Y, 4-6Y and 7-9Y. It illustrates a most revealing tendency of such (dark blue) to move in the direction of [kind of NP that P] (purple) across the three periods. Both constructions increase their distance from co-actional identifiers this and that, as well as the markedly subjective intensifier very, showing the child's increasing ability to employ such in order to construe generalised instantiations based on extended intersubjectivity (see variables controlling for both elements in table 12).

These results support Ghesquiere \& Van de Velde's remarkable intuition (2011) of the intersubjective nature of ID-such as opposed to the more subjective INT-such, as identifying functions of such become increasingly more prominent between the 4th and the 9nth year of age. However, this study also shows that the intersubjective meaning of the ID-such is not merely due to co-actional joint attention, bur rather to the ability to construe 'ad-hoc' generalised instantiations based on extended intersubjectivity (E-I), viz. the socio-cognitive ability to problematise what a general 3rdP would act, feel or think in a specific context. Early stages of E-I construals can shed new 
light on the ontogenetic process of acquisition of social cognition. Corpus-based data focusing on 'surplus' of meaning over co-actional engagement may inform a new gradient understanding of ToM and pragmatic competence during early ontogeny and beyond.

\section{Conclusions}

This paper proposed a gradient and cross-disciplinary approach to the usage-based study of intersubjectivity. It draws from the experimental literature in cognitive psychology and combines it with corpus-based data from language change and ontogenetic development. This method is based on the idea that theory of mind (ToM) is overtly communicated as a 'surplus' of meaning that is additional to individual per-locutionary effects (cf. Searle 1969; Searle \& Vanderveken, 1985) of an utterance. This entails that intersubjectivity can be operationally analysed as a gradient dimension underpinning linguistic elements that are 'unnecessary' for the simplest propositional realisation of a communicative act (viz. entailing a basic 'co-action'), but which are necessary for communicating the awareness of an addressee's or a third party's potential reactions to the utterance. This model allows to distinguish different degrees of intersubjective awareness, ranging from co-actional engagement - merely underpinning joint attention - to more complex and inferential mindreading mechanisms impinging on immediate and extended intersubjectivity. The present case study showed that the pre-nominal such ontogenetically shifts from comparatively more subjective meanings, to more sophisticated identifying functions in which a general social persona's mind (3rdP) is semantically encoded. The surplus approach to 'co-actional' vs 'intersubjective' communication may contribute to a new 'applied turn' of corpus-based research in ToM and ontogenetic development. Similarly, it aims at informing theoretical research on intersubjectivity with a cross-disciplinary method of enquiry.

\section{References}

Apperly, Ian A. 2008. "Beyond simulation-theory and theory-theory: why social cognitive neuroscience should use its own concepts to study "Theory of Mind"." Cognition 107 (1):266-283.

Apperly, Ian. 2010. Mindreaders: the cognitive basis of" theory of mind". New York: Psychology Press.

Apperly Ian. 2013. "Can theory of mind grow up? Mindreading in adults, and its implications for the development and neuroscience of mindreading," in Understanding Other Minds: Perspectives from Developmental Social Neuroscience, eds Baron-Cohen S., Tager-Flusberg H., Lombardo M., editors. (Oxford: Oxford University Press; ), 72-92.

Apperly, Ian A, Elisa Back, Dana Samson, and Lisa France. 2008. "The cost of thinking about false beliefs: Evidence from adults' performance on a non-inferential theory of mind task." Cognition 106 (3):1093-1108.

Author. 2013. XXX. 
Author. 2016a. XXX.

Author. 2016b. XXX.

Author. 2017a. XXX.

Author. 2017b. XXX.

Author et al. 2017. XXX

Baron-Cohen, Simon, Alan M Leslie, and Uta Frith. 1985. "Does the autistic child have a "theory of mind"?" Cognition 21 (1):37-46.

Bowler, Diana E, and Tim G Benton. 2005. "Causes and consequences of animal dispersal strategies: relating individual behaviour to spatial dynamics." Biological Reviews 80 (2):205-225

Bradford, Elisabeth EF, Ines Jentzsch, and Juan-Carlos Gomez. 2015. "From self to social cognition: theory of mind mechanisms and their relation to executive functioning." Cognition 138:21-34.

Breban, Tine. 2010. English adjectives of comparison: Lexical and grammaticalized uses. Vol. 63. Berlin/Boston: Walter de Gruyter.

Brown, Penelope, and Stephen C. Levinson. 1987. Politeness: Some universals in language usage. Vol. 4. Cambridge: Cambridge University Press.

Butterfill, Stephen A, and Ian A Apperly. 2013. "How to construct a minimal theory of mind." Mind \& Language 28 (5):606-637.

Bybee, Joan. 2010. Language, usage and cognition. Cambridge: Cambridge University Press.

Clark, Herbert H., 1996. Using Language. Cambridge University Press, Cambridge.

Cohen, Adam S, Joni Y Sasaki, and Tamsin C German. 2015. "Specialized mechanisms for theory of mind: Are mental representations special because they are mental or because they are representations?" Cognition 136:49-63.

Clark, Herbert H. 1996. Using language, Cambridge University Press. Cambridge

Culpeper, Jonathan. 2011. Impoliteness: Using language to cause offence. Cambridge: Cambridge University Press.

De Clerck, Bernard 2006. The imperative in present-day English: a corpusbased, pragmatic analysis. Universiteit Gent, Gent: BELGIUM.

De Rosnay, MARC, Elian Fink, Sander Begeer, Virginia Slaughter, and Candida Peterson. 2014. "Talking theory of mind talk: young school-aged children's everyday conversation and understanding of mind and emotion." Journal of child language 41 (5):1179-1193

de Ruiter, L. E., Theakston, A. L., Brandt, S., \& Lieven, E. V. (2018). Iconicity affects children's comprehension of complex sentences: The role of semantics, clause order, input and individual differences. Cognition, 171, 202-224.

Diessel, Holger. 2006. "Demonstratives, joint attention, and the emergence of grammar." Cognitive linguistics 17 (4):463-489.

Dumontheil, Iroise, Ian A Apperly, and Sarah-Jayne Blakemore. 2010. "Online usage of theory of mind continues to develop in late adolescence." Developmental science 13 (2):331-338.

Ellis, N. C., \& Larsen-Freeman, D. (2006). Language emergence: Implications for applied linguistics - Introduction to the special issue. Applied linguistics, 27(4), 558-589.

Ferrari, L. and Sweetser, E. 2012. Subjectivity and upwards projection in mental space structure. In B. Dancygier and E. Sweetser (eds.), Mental Spaces and Viewpoint in Grammar and Discourse. Cambridge: Cambridge University Press.

Epley, N., Morewedge, C., and Keysar, B. 2004. Perspective taking in children and adults: Equivalent egocentrism but differential correction. Journal of Experimental Social Psychology, 40, 760-768.

German, T. P., and Hehman, J. A. 2006. Representational and executive selection resources in "theory of mind": Evidence from compromised belief-desire reasoning in old age. Cognition, 101, 129-152. 
Ghesquière, Lobke, and Freek Van de Velde. 2011. "A corpus-based account of the development of English such and Dutch zulk: Identification, intensification and (inter) subjectification." Cognitive Linguistics 22 (4):765-797.

Ghesquière, Lobke, Lieselotte Brems, and Freek Van de Velde. 2012. "Intersubjectivity and intersubjectification: Typology and operationalization." English Text Construction 5 (1):128-152.

Givón, Talmy. 2009. The genesis of syntactic complexity: Diachrony, ontogeny, neuro-cognition, evolution. Amsterdam: John Benjamins Publishing.

Goldman, Alvin I. 2006. Simulating minds: The philosophy, psychology, and neuroscience of mindreading. Oxford: Oxford University Press.

Grant, Cathy M, Kevin J Riggs, and Jill Boucher. 2004. "Counterfactual and mental state reasoning in children with autism." Journal of autism and developmental disorders 34 (2):177-188.

Gries, Stefan Th, and Anatol Stefanowitsch. 2004. "Extending collostructional analysis: A corpusbased perspective onalternations'." International journal of corpus linguistics 9 (1):97-129.

Gries, Stefan Th. 2010. "Behavioral profiles: A fine-grained and quantitative approach in corpusbased lexical semantics." The Mental Lexicon 5 (3):323-346.

Gries, Stefan Th, and Naoki Otani. 2010. "Behavioral profiles: A corpus-based perspective on synonymy and antonymy." ICAME Journal 34:121-150.

Gries, Stefan Th. 2015. "More (old and new) misunderstandings of collostructional analysis: On Schmid and Küchenhoff (2013)." Cognitive Linguistics 26 (3):505-536.

Happe, Francesca GE. 1995. "The role of age and verbal ability in the theory of mind task performance of subjects with autism." Child development 66 (3):843-855.

Hilpert, Martin. 2006. "Distinctive collexeme analysis and diachrony." Corpus Linguistics and Linguistic Theory 2 (2):243-256.

Husserl, Edmund. [1936]1970. The crisis of European sciences and transcendental phenomenology. Evanston, IL: Northwestern University Press.

Jansegers, Marlies, and Stefan Th Gries. Forthcoming. "Towards a dynamic behavioral profile: A diachronic study of polysemous sentir in Spanish." Corpus Linguistics and Linguistic Theory.

Kasper, Gabriele. 1990. "Linguistic politeness: Current research issues." Journal of pragmatics 14 (2):193-218.

Kovács, Ágnes Melinda, Ernő Téglás, and Ansgar Denis Endress. 2010. "The social sense: Susceptibility to others' beliefs in human infants and adults." Science 330 (6012):18301834.

Langacker, Ronald W. 1987. Foundations of cognitive grammar: Theoretical prerequisites. Vol. I. Stanford, CA: Stanford University Press.

Langacker, Ronald W. 1990. "Subjectification." Cognitive Linguistics 1 (1):5-38.

Langacker, Ronald W. 1991. Foundations of cognitive grammar: Descriptive application. Vol. II. Standford: Stanford University Press.

Langacker, Ronald W. 2005. Dynamicity, Fictivity, and Scanning: The Imaginative Basis of Logic and Linguistic Meaning. In Diane Pecher \& Rolf A. Zwaan (eds.), Grounding Cognition: The Role of Perception and Action in Memory, Language and Thinking. Cambridge: Cambridge University Press. $164-197$.

Langacker, R. W. 2009. Investigations in cognitive grammar. Berlin: Walter de Gruyter.

McCafferty, S. G.1998. 'Nonverbal expression and L2 private speech,' Applied Linguistics 19: 7396.

MacWhinney, B. (2006). Emergentism — use often and with care. Applied linguistics, 27(4), 729740.

Moll, Henrike, and Michael Tomasello. 2007. "How 14-and 18-month-olds know what others have experienced." Developmental psychology 43 (2):309-317. 
Mori, J., \& Hayashi, M. (2006). The achievement of intersubjectivity through embodied completions: A study of interactions between first and second language speakers. Applied linguistics, 27(2), 195-219.

Narrog, Heiko. 2012. "Beyond intersubjectification: Textual usages of modality and mood in subordinate clauses as part of speech orientation." English Text Construction 5 (1):29-52

Norén, K. \& Linell, P. 2007. Meaning potentials and the interaction between lexis and grammar. Some empirical substantiations. Pragmatics, 17: 387-416.

Nuyts, Jan. 2001a. "Subjectivity as an evidential dimension in epistemic modal expressions." Journal of Pragmatics 33:383-400.

Nuyts, Jan. 2001b. Epistemic modality, language, and conceptualization: a cognitive-pragmatic perspective. Amsterdam: John Benjamins.

Nuyts, Jan. 2012. "Notions of (inter) subjectivity." English Text Construction 5 (1):53-76.

O'Neill, Daniela K. 1996. "Two-year-old children's sensitivity to a parent's knowledge state when making requests." Child development:659-677.

Onishi, Kristine H, and Renée Baillargeon. 2005. "Do 15-month-old infants understand false beliefs?" Science 308 (5719):255-258.

Perner, Josef, Susan R Leekam, and Heinz Wimmer. 1987. "Three-year-olds' difficulty with false belief: The case for a conceptual deficit." British Journal of Developmental Psychology 5 (2):125-137.

Perner, Josef, and Ted Ruffman. 2005. "Infants' insight into the mind: How deep?" Science 308 (5719):214-216.

Povinelli, D. J., and S. Giambrone. 1999. Inferring other minds: Failure of the argument by analogy. Philosophical Topics, 27, 167-201.

Povinelli, D. J., and J. Vonk. 2004. We don't need a microscope to explore the chimpanzee's mind. Mind \& Language, 19, 1-28."

Premack, David, and Guy Woodruff. 1978. "Does the chimpanzee have a theory of mind?" Behavioral and brain sciences 1 (04):515-526.

Reich, Wendelin. 2011. "The cooperative nature of communicative acts." Journal of Pragmatics 43 (5):1349-1365.

Reich, Wendelin. 2012. "In defense of the evolutionary approach to human communication: Reply to Huang and Wu." Journal of Pragmatics 44 (1):123-125.

Rizza, C. (2009). Semantically Redundant Language-A Case Study. Applied linguistics, 30(2), 276-294.

Rychlý, Pavel. 2008. "A lexicographer-friendly association score." In Proceedings of Recent Advances in Slavonic Natural Language Processing, RASLAN edited by P. Sojka and A. Horák, 6-9. Brno, Czech Republic: Masaryk University.

Schaafsma, Sara M, Donald W Pfaff, Robert P Spunt, and Ralph Adolphs. 2015. "Deconstructing and reconstructing theory of mind." Trends in cognitive sciences 19 (2):65-72.

Schneider, Dana, Virginia P Slaughter, and Paul E Dux. 2015. "What do we know about implicit false-belief tracking?" Psychonomic bulletin \& review 22 (1):1-12.

Schutz, Alfred. 1962. Commonsense and scientific interpretations of human action. In Alfred Schutz, Collected Papers, vol. 1, 3-47. The Hague: Martinus Nijhoff.

Searle, J. R. (1969). Speech acts: An essay in the philosophy of language (Vol. 626). Cambridge: Cambridge University press.

Searle, J. R., \& Vanderveken, D. (1985). Foundations of illocutionary logic. Cambridge: Cambridge Universirty Press.

Stefanowitsch, Anatol, and Stefan Th Gries. 2003. "Collostructions: Investigating the interaction of words and constructions." International journal of corpus linguistics 8 (2):209-243.

Stich, Stephen, and Shaun Nichols. 1997. "Cognitive penetrability, rationality and restricted simulation." Mind \& Language 12 (3-4):297-326. 
Surian, Luca, Stefania Caldi, and Dan Sperber. 2007. "Attribution of beliefs by 13-month-old infants." Psychological science 18 (7):580-586.

Tomasello, M. 2008. The origins of human communication. Cambridge: MA: MIT Press.

Traugott, E. C. 2003. "From subjectification to intersubjectification." In Motives for language change, edited by R. Hickey. Cambridge: Cambridge University Press.

Traugott, E. C. 2010. "Revisiting subjectification and intersubjectification." In Subjectification, intersubjectification and grammaticalization, edited by K. Davidse and L. Vandelanotte. Berlin: De Gruyter Mouton.

Traugott, Elizabeth C. 2012. "Intersubjectification and clause periphery." English Text Construction 5 (1):7-28.

Traugott, Elizabeth Closs, and Richard B. Dasher. 2002. Regularity in semantic change. Cambridge: Cambridge University Press.

Trillo, Jesús Romero. 1997. "Your attention, please: Pragmatic mechanisms to obtain the addressee's attention in English and Spanish conversations." Journal of Pragmatics 28 (2):205-221.

Van Olmen, Daniel. 2010. "Typology meets usage: The case of the prohibitive infinitive in Dutch." Folia Linguistica 44 (2):471-507.

Verhagen, Arie. 2005. Constructions of Intersubjectivity: Discourse, syntax and cognition. Oxford: Oxford University Press.

Verhagen, Arie. 2007. Construal and perspectivisation. In: D. Geeraerts \& H. Cuyckens (Eds.), Handbook of Cognitive Linguistics. Oxford: Oxford University Press

Ziegeler, Debra. 1997. "Retention in ontogenetic and diachronic grammaticalization." Cognitive Linguistics 8 (3):207-242.

Zlatev, Jordan. 2008. "From proto-mimesis to language: Evidence from primatology and social neuroscience." Journal of Physiology-Paris 102 (1):137-151.

Zlatev, Jordan, Elainie Alenkær Madsen, Sara Lenninger, Tomas Persson, Susan Sayehli, Göran Sonesson, and Joost van de Weijer. 2013. "Understanding communicative intentions and semiotic vehicles by children and chimpanzees." Cognitive development 28 (3):312-329.

Wilkinson, Meredith R, and Linden J Ball. 2012. "Why studies of autism spectrum disorders have failed to resolve the theory theory versus simulation theory debate." Review of Philosophy and Psychology 3 (2):263-291.

Wimmer, Heinz, and Josef Perner. 1983. "Beliefs about beliefs: Representation and constraining function of wrong beliefs in young children's understanding of deception." Cognition 13 (1):103-128. 